\title{
Alterations in nucleotide and pyrophosphate levels in Phytophthora palmivora following exposure to the antifungal agent potassium phosphonate (phosphite)
}

\author{
Julia M. Griffith, ${ }^{*}$ Robert H. Smillie and Bruce R. Grant \\ Department of Biochemistry, University of Melbourne, Parkville, Victoria 3052, Australia
}

(Received 27 November 1989; accepted 16 March 1990)

\begin{abstract}
Short exposure (up to $3 \mathrm{~h}$ ) of phosphate-starved mycelium from Phytophthora palmivora to the antifungal agent potassium phosphonate resulted in decreased levels of NAD, ATP, and a number of compounds tentatively identified as polyphosphorylated nucleotides ('alarmones'). ADP, AMP and adenosine levels were not increased, as would be expected if phosphorylation were the site of inhibition. Pyrophosphate levels, however, were raised. The incorporation of ${ }^{32} \mathrm{P} \mid$ phosphate into phospholipids and other macromolecules was not affected during this short exposure. Together, these results suggest that adenylate synthesis may be a primary site of action of phosphonate in the fungus.
\end{abstract}

\section{Introduction}

Diseases of plants caused by fungi belonging to the class Oomycetes have proved difficult to control by chemical means. Recently, a number of fungicides have been developed which are effective against these fungi (see reviews by Cohen \& Coffey, 1986; Schwinn \& Urech, 1986; Schwinn \& Staub, 1987). One of these was aluminium ethylphosphonate (Aliette, syn. Fosetyl-Al produced by Rhone-Poulenc LA; Williams et al., 1977). Subsequently, aluminium ethylphosphonate was found to be degraded rapidly in soil and plant tissue to ethanol and phosphonate (Cohen \& Coffey, 1986. [The term phosphorous acid (phosphite) has been widely used as a synonym for phosphonic acid (Ouimette \& Coffey, 1989).] Phosphonate is now accepted as the active component of aluminium ethylphosphonate. It is as effective as aluminium ethylphosphonate in controlling several plant diseases in the field (Pegg et al., 1985; Rohrbach \& Schenck, 1985; Walker, 1988; Ouimette \& Coffey, 1989).

The mode of action of phosphonate in susceptible fungi is not known. Phosphonates appear to be fungistatic rather than fungicidal (Schwinn \& Staub, 1987) and the action of plant defences may be necessary to achieve complete control in the host-parasite situation (Smillie et

Abbreviations: LPR, low-phosphate medium; 0PR, zero-phosphate medium; PEI, polyethyleneimine; PRPP, 5'-phospho- $\alpha$-D-ribose 1pyrophosphate. $a l ., 1989 a$ ). Alterations of the fungal surface are induced by phosphonate (R. H. Dunstan, personal communication) and may enable the plant to mount a more effective defence response (Saindrenan et al., 1988; Smillie et al., $1989 b$; Dercks \& Creaser, 1989). Studies to date show that phosphonate has a wide range of effects on susceptible fungi. Mycelia grown in its presence are severely deformed (Abu-jawdah, 1983; Dercks \& Buchenauer, 1987; J. M. Griffith \& B. R. Grant, unpublished), and numbers of sporangia and oospores are reduced (Coffey \& Joseph, 1985). Cysts derived from phosphonate-grown sporangia produce severely stunted germ-tubes on germination (J. M. Griffith, unpublished). Dercks \& Buchenauer (1987) found that aluminium ethylphosphonate disturbed cell wall synthesis and phospholipid metabolism. In our laboratory, ${ }^{31}$ P-NMR studies have shown that phosphonate treatment of Phytophthora palmivora resulted in marked alterations in the distribution of several phosphorus components, including a reduction in the chain length of polyphosphates (Niere et al., 1990); R. H. Dunstan (personal communication), using GC-mass spectroscopy, has found perturbations in lipid composition, cell wall material and a number of intermediary metabolites in $P$. palmivora growing in the presence of sub-toxic concentrations of phosphonate. In this paper, we report the effects of short-term exposure to phosphonate on the metabolism of this organism.

A preliminary report of part of this work was presented to the Mediterranean Phytopathological 
Union Conference at Palermo, Sicily, April, 1989 (Smillie et al., 1989b).

\section{Methods}

Organism. The strain of Phytophthora palmivora (Butl.) Butl., ATCC 26286 , and the methods used for routine culture have been described previously (Grant $e$ t al., 1984, 1985).

Growth of mycelia. The media used and the conditions for the growth of the organism are described by Griffith et al. (1989a). Briefly, the media used were a low- $P_{i}$ medium (termed 'LPR'), which contained $0.1 \mathrm{mM} P_{\mathrm{i}}$, and zero-phosphate medium (termed ' $0 P R^{\prime}$ ') containing no $P_{\mathrm{i}}$. The fungus was grown in $50 \mathrm{ml} \mathrm{LPR}$ medium in $250 \mathrm{ml}$ flasks for $7 \mathrm{~d}$ at $26^{\circ} \mathrm{C}$. The dry weight at harvest was approximately $30 \mathrm{mg}$ per flask.

Mycelium from each flask was harvested by filtration onto glassfibre paper (Whatman GF/C), washed with three $15 \mathrm{ml}$ volumes of distilled water at room temperature, and placed in $100 \mathrm{ml} 0 \mathrm{PR}$ medium (diluted $1: 3$ with distilled water) in a $250 \mathrm{ml}$ flask. Flasks were shaken at 100 oscillations $\min ^{-1}$ at $26^{\circ} \mathrm{C}$. Non-radioactive $P_{i}$ was added ( $1 \mu \mathrm{mol}$ per flask) and the mycelium shaken for $1 \mathrm{~h}$. Then, $100 \mu \mathrm{mol}$ potassium phosphonate (pH 6.2) was added to the test flasks. Fifteen minutes later (termed 'zero time'), $5 \mu \mathrm{mol}$ of ${ }^{32} \mathbf{P}_{i}$ (specific activity approx. $120 \mathrm{TBq} \mathrm{mol}^{-1}$ ) was added to both control and test flasks. The mycelium was then harvested after a designated interval (generally $3 \mathrm{~h}$ later).

Extraction of mycelium. (a) Cold perchloric acid (PCA) extraction. Mycelia, washed as described above, were snap-frozen in liquid nitrogen. Ten millilitres of ice-cold $7 \%(\mathrm{v} / \mathrm{v})$ PCA was added and the sample held at $-20^{\circ} \mathrm{C}$ for approximately $1 \mathrm{~h}$. It was then allowed to thaw in ice, homogenized for $1 \mathrm{~min}$ using an Ultra-Turrax homogenizer (Janke \& Kunkel, West Germany) and the mycelial fragments removed by filtration. The resulting solution was neutralized to $\mathrm{pH} 7$ with $\mathrm{KOH}$ and passed through Whatman no. 1. filter paper to remove the $\mathrm{KClO}_{4}$ precipitate. The filtrate was freeze-dried, redissolved in water, and a further batch of $\mathrm{KClO}_{4}$ crystals removed by centrifugation. The latter procedure was repeated and the filtrate made to a known final volume $(0.5$ or $1.0 \mathrm{ml})$. Samples were stored at $-20^{\circ} \mathrm{C}$ prior to assay.

(b) Cold formic acid extraction. The washed mycelia were frozen in liquid nitrogen. Then $10 \mathrm{ml}$ ice-cold $1 \mathrm{M}$-formic acid (Payne \& Ames, 1982) was added to each sample, and the samples held at $-20^{\circ} \mathrm{C}$ for $1 \mathrm{~h}$. The samples were then thawed and homogenized as described above. The mycelial fragments were removed by filtration, and the resulting solution was freeze-dried and made to a final volume of $1 \mathrm{ml}$ with water.

(c) Chloroform/methanol (lipid), KOH and hot PCA extractions. These were done essentially as described by Niere et al. (1990), except that the hot PCA extraction was for $3 \mathrm{~h}$ at $85^{\circ} \mathrm{C}$, rather than in a boiling water bath for $1 \mathrm{~h}$.

Radioactivity. The amount of radioactive phosphorus in the various fractions was determined either by Cerenkov counting or by scintillation counting using an LKB 1217 scintillation counter.

Chemicals. Nucleotides and tetrabutylammonium hydroxide were obtained from Sigma. Phosphorous acid (phosphonate) was from Albright \& Wilson (Aust.) Ltd. Methanol (liquid chromatography grade) was from Millipore (Aust.). ${ }^{32} \mathrm{P}_{\mathrm{i}}$ was obtained from the Australian Atomic Energy Commission, Lucas Heights, NSW. It was assumed to be carrier-free and was added to non-radioactive stock solutions to give a specific activity in the range of $120 \mathrm{TBq} \mathrm{mol}^{-1}$. [ $\left.{ }^{32} \mathrm{P}\right] A T P$ was from Bresa Ltd. (South Australia). [ ${ }^{32}$ P]Pyrophosphate and $\left[{ }^{32} \mathrm{P}\right]$ tripolyphosphate were prepared by heating a freeze-dried sample of potassium $[32 \mathrm{P}]$ phosphate at $400{ }^{\circ} \mathrm{C}$ in a muffle furnace for $1 \mathrm{~h}$.
Thin-layer chromatography. Thin-layer chromatography of cold PCA and formic acid extracts was done on poly(ethyleneimine)-cellulose (PEI-cellulose) plates containing a fluorescent indicator (Merck), using the two-dimensional system of Randerath \& Randerath (1964). Chromatography of lipid extracts was done on silica gel-60 aluminium plates without a fluorescent indicator (Merck), using the twodimensional system of Wassef \& Hendrix (1977). Radioactive compounds were visualized by autoradiography (Griffith $e t$ al., 1989a) and quantified using a computing densitometer model 300A (Molecular Dynamics, California, USA). Non-radioactive markers were located by UV absorption (nucleotides) or by phosphomolybdate sprays (phosphorus esters) - that of Bochner et al. (1981) was used for the PEI-cellulose plates and that of Rosenberg (1959) for the silica gel plates. Phosphatidylcholine, -ethanolamine, -serine and -inositol, and 'ceramide-AEP' were identified by their colour reaction with specific sprays (Kates, 1982) and their positions on chromatography (Hendrix \& Rouser, 1976; Wassef \& Hendrix, 1977; Kates, 1982; Renkonen \& Luukkonen, 1976). The sprays used were Dragendorff, ninhydrin and orcinol reagents. A number of minor spots were not identified.

Paper electrophoresis. Electrophoresis and autoradiography were done as described by Griffith et al. (1989a).

High-pressure liquid chromatography (HPCL). This was done using two reverse-phase columns in series $(100 \mathrm{~mm}$ and $50 \mathrm{~mm}$ in length, $4 \mathrm{~mm}$ internal diameter, $5 \mu \mathrm{m}$ particle size; Scientific Glass Engineering Ltd, Aust.). Compounds were detected by changes in UV absorbance at $254 \mathrm{~nm}$ using a Beckman model 160 absorbance detector and radioactivity was measured using a LKB-Wallac 1208 Betacord radioactivity monitor. Gradients were generated using two Waters M-45 solvent delivery systems and a model 660 solvent programmer. Generally, the solvent delivery programme no. 5 was used. Data were acquired and analysed using a chromatography program (DAPA Scientific Software, Australia). Solvent A consisted of 4 mM-tetrabutyl ammonium hydroxide in $0.1 \mathrm{M}-\mathrm{KH}_{2} \mathrm{PO}_{4}$ buffer, $\mathrm{pH} \mathrm{6.00}$. Solvent $\mathrm{B}$ consisted of $50 \%(\mathrm{v} / \mathrm{v})$ methanol and $50 \%(\mathrm{v} / \mathrm{v}) 0 \cdot 1 \mathrm{M}-\mathrm{KH}_{2} \mathrm{PO}_{4}$,

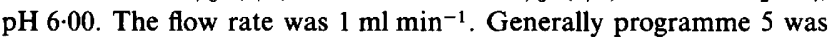
used, and the volume of samples analysed was $20 \mu \mathrm{l}$. The optimal chromatographic conditions varied slightly between different experiments. The actual conditions used are indicated in the text.

\section{Results}

\section{Distribution of phosphorus-labelled material in mycelium}

$\mathbf{P}_{\mathrm{i}}$ deprivation was used to introduce high levels of phosphonate rapidly into $P$. palmivora (Griffith et al., $1989 a, b)$. Its effect on phosphorus metabolism was then studied over a period of several hours.

Initial results, using $\mathrm{P}_{\mathrm{i}}$-deprived mycelium (Griffith et al., 1989a), were variable. In some cases, addition of phosphonate caused such a severe depression in phosphorus metabolism that very little ${ }^{32} \mathrm{P}_{\mathrm{i}}$ was assimilated. Consistent results were obtained when a small amount of non-labelled $\mathbf{P}_{\mathrm{i}}(1 \mu \mathrm{mol})$ was added to the fungus $1 \mathrm{~h}$ before the addition of $100 \mu \mathrm{mol}$ phosphonate. (Preliminary studies showed that most of the $P_{i}$ had been taken up by the time the ${ }^{32} \mathbf{P}_{i}$ was added.) After the addition of phosphonate, the fungus was shaken for a further $15 \mathrm{~min}$ before the ${ }^{32} \mathbf{P}_{\mathrm{i}}(5 \mu \mathrm{mol})$ was added. $\mathbf{P}_{\mathrm{i}}$ concentrations 


\section{Table 1. ${ }^{32} P$ distribution in mycelium of $P$. palmivora}

Mycelia from eight flasks of LPR medium were treated in separate flasks for $1 \mathrm{~h}$ with $1 \mu \mathrm{mol}$ non-labelled $\mathrm{P}_{\mathrm{i}}$. Half were then given $100 \mu \mathrm{mol}$ phosphonate for $15 \mathrm{~min}$, then $5 \mu \mathrm{mol}{ }^{32} \mathrm{P}_{\mathrm{i}}$ was added to all flasks. After $3 \mathrm{~h}$, the mycelia were harvested, washed, and frozen in liquid $\mathrm{N}_{2}$. The mycelia were extracted with ice-cold PCA, then chloroform/methanol, $0 \cdot 1 \mathrm{M}-\mathrm{KOH}$, and hot PCA. The distribution of the ${ }^{32} \mathrm{P}$ in the various fractions was then determined. The results are the means of four flasks, \pm SEM.

\begin{tabular}{lcc}
\hline \hline & \multicolumn{2}{c}{$32 \mathrm{P}$ recovered (nmol) } \\
\cline { 2 - 3 } Fraction & Control & $\begin{array}{c}\text { Phosphonate } \\
\text { treated }\end{array}$ \\
\hline Cold PCA & $540 \cdot 3 \pm 152$ & $488 \cdot 2 \pm 145$ \\
Lipid & $59 \cdot 1 \pm 22 \cdot 0$ & $56 \cdot 7 \pm 9 \cdot 5$ \\
$0 \cdot 1$ M-KOH & $105 \cdot 0 \pm 28 \cdot 3$ & $85 \cdot 4 \pm 13 \cdot 4$ \\
Hot PCA & $28 \cdot 2 \pm 6 \cdot 9$ & $23 \cdot 0 \pm 4 \cdot 1$ \\
Pellet & $2 \cdot 3 \pm 0 \cdot 6$ & $1 \cdot 5 \pm 0 \cdot 3$ \\
Total in & & \\
mycelium & $734.9 \pm 202 \cdot 6$ & $654.8 \pm 167 \cdot 5$ \\
Remaining & & \\
in medium & $3270 \pm 435$ & $3400 \pm 187$ \\
Recovery & $80 \cdot 1 \%$ & $81 \cdot 1 \%$ \\
\hline \hline
\end{tabular}

Table 2. ${ }^{32} P$ distribution in lipids from $P$. palmivora

Phospholipids, prepared from the mycelia used in the experiment shown in Table 1, were separated on silica gel plates using a twodimensional system. Autoradiographs were prepared and the spots were quantified using a densitometer. The results, in arbitrary units, are the means of four separate extracts of mycelium, \pm SEM.

\begin{tabular}{|c|c|c|}
\hline Phospholipid & Control & $\begin{array}{l}\text { Phosphonate } \\
\text { treated }\end{array}$ \\
\hline Phosphatidic acid & $7 \cdot 1 \pm 3 \cdot 8$ & $5 \cdot 9 \pm 4 \cdot 3$ \\
\hline $\begin{array}{l}\text { Phosphatidyl- } \\
\text { ethanolamine }\end{array}$ & $7.8 \pm 1.8$ & $7 \cdot 9 \pm 1 \cdot 1$ \\
\hline $\begin{array}{l}\text { Phosphatidyl- } \\
\text { serine and -inositol }\end{array}$ & $5 \cdot 2+2 \cdot 6$ & $6 \cdot 4 \pm 2 \cdot 6$ \\
\hline 'Ceramide-AEP'* & $8 \cdot 4+2 \cdot 5$ & $7.5+1.8$ \\
\hline Phosphatidylcholine & $10 \cdot 7+2 \cdot 2$ & $11 \cdot 1+1 \cdot 6$ \\
\hline Unknown 1 & $0.6 \pm 0.3$ & $0.3 \pm 0.2$ \\
\hline Unknown 2 & $1.2 \pm 0.8$ & $1.2 \pm 1.6$ \\
\hline Unknown 3 & $1.6 \pm 1.8$ & $1.6 \pm 1.7$ \\
\hline
\end{tabular}

* This compound has been identified as a phosphonolipid (Wassef \& Hendrix, 1977; Creamer \& Bostock, 1986), but ${ }^{31}$ P-NMR studies have failed to reveal any peaks corresponding to phosphonolipids (Niere et al., 1990).

were maintained at low levels, since micromolar concentrations of $\mathbf{P}_{\mathrm{i}}$ significantly inhibit phosphonate uptake in this strain of $P$. palmivora (Griffith et al., 1989b; cf. Barchietto et al., 1988, 1989).

Three hours after the addition of the ${ }^{32} \mathrm{P}_{i}$, phosphonate had not altered the distribution of ${ }^{32} \mathrm{P}$ between the major fractions extracted from the mycelium (Table 1). Further fractionation of the phospholipid components failed to reveal any major differences between the treated and the non-treated samples (Table 2). However, paper electrophoresis of the cold PCA extract showed that some bands were reduced in the phosphonate-treated samples (data not shown).

\section{Reverse-phase chromatography of acid-soluble material}

The PCA extracts were further fractionated using a reverse-phase HPLC system. The results of a typical experiment are shown in Figs 1-3. Fig. 1 shows the UV absorbance profile of material at 'zero time', just before the addition of ${ }^{32} \mathrm{P}_{\mathrm{i}}$. At this stage $(15 \mathrm{~min}$ exposure to phosphonate), there were no detectable differences between the phosphonate-treated material and the control. However, after $3 \mathrm{~h}$ incubation in the presence of ${ }^{32} \mathrm{P}_{\mathrm{i}}$, there was a marked reduction in the concentration of compounds running in the positions of ATP and of NAD (Figs 2 and 3). The concentrations of a number of compounds eluting near ATP were also reduced. Although these compounds were highly labelled (Fig. 3), their UV absorbance was low compared with ATP (Fig. 2). A ${ }^{32} \mathrm{P}$-labelled peak eluting just after $P_{i}$ also increased

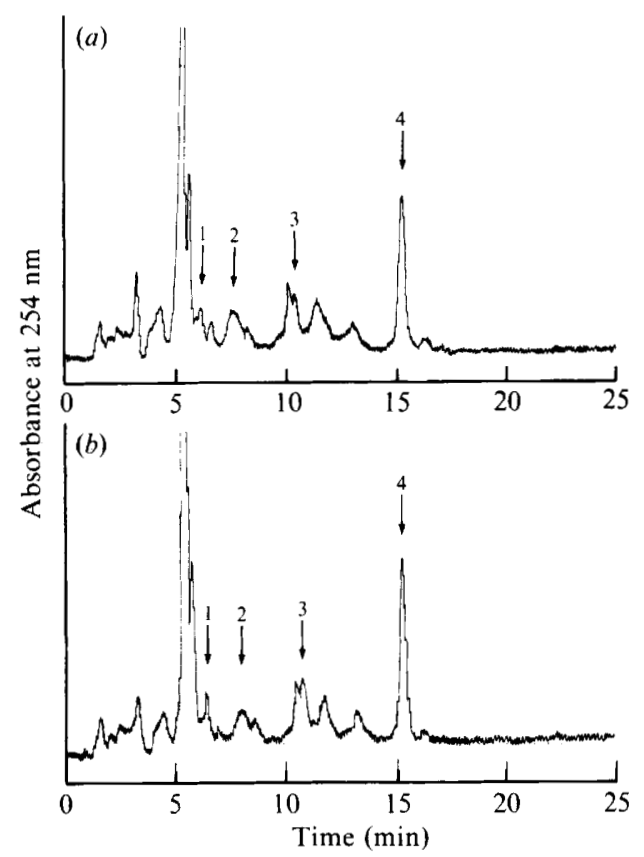

Fig. 1. UV absorbance profile of PCA extracts from $P$. palmivora mycelium harvested at 'zero time'. Two samples of mycelia from phosphorus-deficient medium were treated with $1 \mu \mathrm{mol}$ non-radioactive $P_{i}$ for 1 h. Potassium phosphonate $(100 \mu \mathrm{mol})$ was then added to one of the samples, and after a further $15 \mathrm{~min}$ both samples were harvested ('zero time'). PCA extracts were prepared and the material fractionated on HPLC (15 min run, $40 \%$ solvent B). (a) Control; (b) phosphonate-treated. The identity of the markers indicated by arrows is: 1 , NAD; 2, adenosine/AMP; 3, ADP; 4, ATP. 


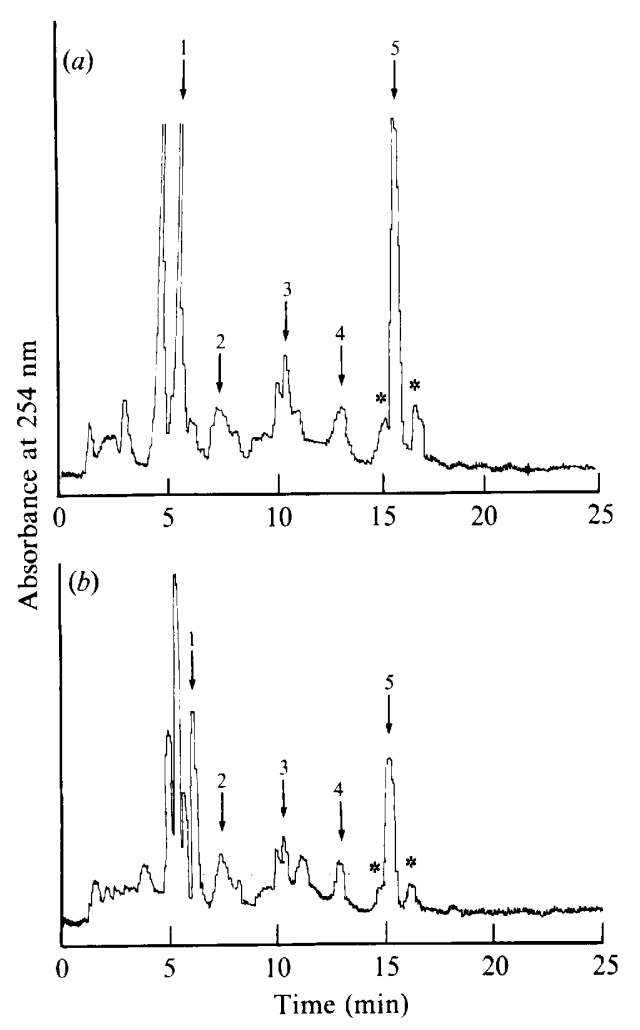

Fig. 2. UV absorbance profile of PCA extracts from $P$. palmivora mycelium harvested $3 \mathrm{~h}$ after the addition of ${ }^{32} \mathrm{P}_{\mathrm{i}}$. Conditions were as described for Fig. 1, except that $5 \mu \mathrm{mol}{ }^{32} \mathrm{P}_{\mathrm{i}}$ was added at 'zero time'. (a) Control; (b) phosphonate-treated. The arrows indicate the positions of the following compounds: 1, NAD; 2, adenosine/AMP; 3, ADP; 4, not identified; 5, ATP. The compounds tentatively identified as polyphosphorylated nucleotides ('alarmones') are indicated with an asterisk.

after phosphonate treatment (Fig. $3 b$ ). This peak had little, if any, UV absorbance.

The positions of NAD, ADP and ATP were confirmed by spiking the extracts with authentic nucleotides (including [ $\left.{ }^{32} \mathrm{P}\right] \mathrm{ATP}$ ). The concentrations of NAD and ATP in the phosphonate-treated material were about half those of the control (data not shown). In another experiment using ${ }^{32} \mathrm{P}_{\mathrm{i}}$ of higher specific activity (approx. $400 \mathrm{TBq} \mathrm{mol}{ }^{-1}$ ), differences in NAD and ATP levels could be detected as early as $30 \mathrm{~min}$ after the addition of ${ }^{32} \mathrm{P}_{\mathrm{i}}$.

Charcoal-treatment of the PCA extracts at acid $\mathrm{pH}$ resulted in the disappearance of almost all of the UVabsorbing material (Fig. $4 a, c$ ), including the peaks with the high level of radioactivity and low UV absorbance (Fig. $4 b, d$ ). Based on this observation and on their position in two-dimensional thin-layer chromatography (see below), these compounds have been tentatively identified as polyphosphorylated nucleotides (see Discussion). Formic acid has been used to extract these types of compounds from bacteria (Payne \& Ames, 1982).

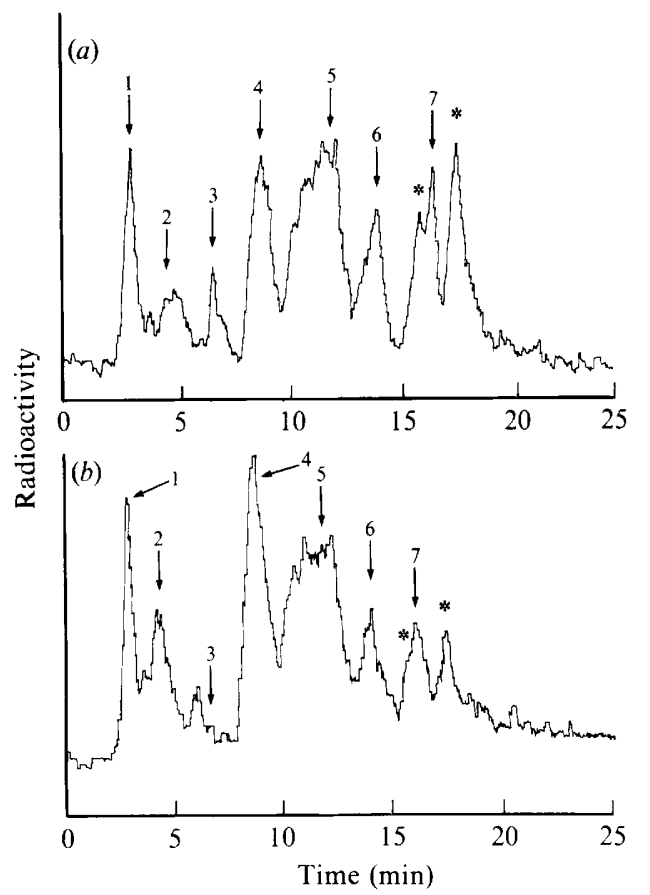

Fig. 3. ${ }^{32} \mathrm{P}$ profile of PCA extracts from $P$. palmivora mycelium harvested $3 \mathrm{~h}$ after the addition of ${ }^{32} \mathrm{P}_{\mathrm{i}}$. This profile was determined concurrently with the UV absorbance profile presented in Fig. 2, and has been adjusted for the time difference between the UV and radioactivity monitors. (a) Control; (b) phosphonate-treated. The arrows indicate the positions of the following compounds: $1, \mathrm{P}_{\mathrm{i}} ; 2$, pyrophosphate; 3, NAD (determined from Fig. 2); 4, tripolyphosphate; 5, 6, not identified; 7, ATP. The compounds tentatively identified as polyphosphorylated nucleotides ('alarmones') are indicated with an asterisk.

However, we did not find these compounds in formic acid extracts of $P$. palmivora.

A number of radioactive compounds, however, were not adsorbed by charcoal (Fig. 4d). As shown in Fig. 3, peaks 1,2 and 4 co-chromatographed with $\left.\mathrm{P}_{\mathrm{i}},{ }^{32} \mathrm{P}\right]$ pyrophosphate and $\left[{ }^{32} \mathrm{P}\right]$ tripolyphosphate respectively. It seems probable that some of the other unidentified peaks are higher polyphosphates, since these are known to be present in this organism (Niere et al., 1990).

\section{Two-dimensional thin-layer chromatography of acid- soluble material}

PCA- and formic-acid-extracted material was chromatographed on PEI-cellulose plates. It was possible to identify most of the spots by co-chromatography with known standards. Charcoal-treatment resulted in the disappearance of those spots tentatively identified as nucleotides. Similarly, heat-treatment $(10 \mathrm{~min}$ in $1 \mathrm{M}$ $\mathrm{HCl}$ at $100{ }^{\circ} \mathrm{C}$ ) resulted in hydrolysis of all compounds, except that identified as fructose 1,6-bisphosphate, which was reduced in intensity, and a small spot 

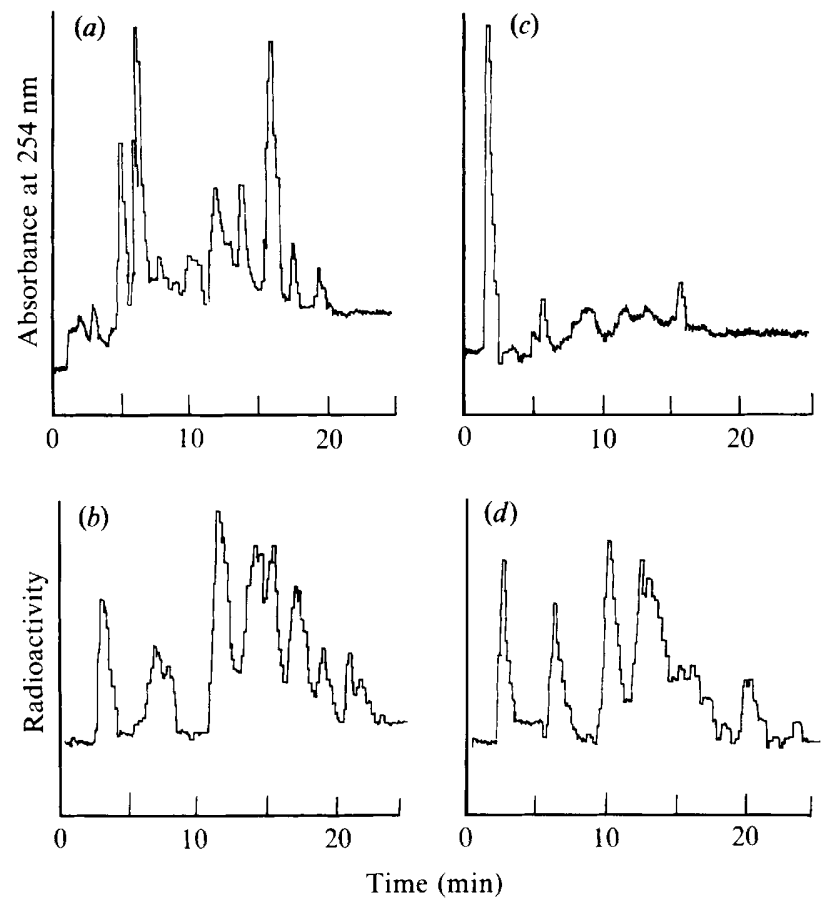

Fig. 4. UV absorbance and ${ }^{32} \mathrm{P}$ profiles of PCA extracts from $P$. palmivora mycelium before and after charcoal-treatment. PCA extracts were prepared from mycelium incubated in the presence of $5 \mu \mathrm{mol}^{32} \mathrm{P}_{\mathrm{i}}$, as described in the text. A $0.2 \mathrm{ml}$ portion of the material was acidified by the addition of an equal volume of $5 \%(\mathrm{v} / \mathrm{v})$ formic acid, and charcoal (approx. $10 \mathrm{mg}$ ) was added. The charcoal was removed by centrifugation (Microfuge, $2 \mathrm{~min}$ at 10000 r.p.m.) followed by filtration through a $0.45 \mu \mathrm{m}$ membrane (Millipore). The extract was then fractionated by HPLC and the UV absorbance and ${ }^{32} \mathrm{P}$ profiles determined. Chromatographic conditions: 15 min run, $35 \%$ solvent $\mathbf{B}$. $(a, b)$ Material before charcoal-treatment: (a) UV absorbance profile; (b) ${ }^{32} \mathrm{P}$ profile. $(c, d)$ Material after charcoal-treatment: (c) UV absorbance profile; $(d){ }^{32} \mathrm{P}$ profile. Note: The data for $(c)$ and $(d)$ have been corrected for dilution; the new peak at the solvent front in $(c)$ results from the added formic acid.

migrating in the region of $\alpha$-glycerophosphate (cf. Nelson \& Kornberg, 1970). Exposure to phosphonate resulted in a reduction in the levels of ATP, of material running in the region of polyphosphates (Lusby \& McLaughlin, 1980) and the polyphosphorylated nucleotides (Cashel \& Gallant, 1969), and of an unidentified spot which migrated at the solvent front. Fructose 1,6bisphosphate was present at approximately the same level in both treated and control material. The concentration of pyrophosphate, however, had almost doubled in phosphonate-treated material. It was not possible to identify precisely which spot corresponded to NAD, as this compound co-chromatographed with $\alpha$-glycerophosphate. It was clear, however, that the amount of radioactivity migrating in the region of NAD was very low. Subsequent fractionation of these extracts on HPLC using a shallower gradient (programme no. 6) revealed that there were several radioactive compounds eluting in the region of NAD (data not shown). These peaks may include fructose 1,6-bisphosphate.

\section{Discussion}

The present work indicates that, initially, the addition of phosphonate to $P$. palmivora mycelium alters the synthesis of only a few phosphorus-containing compounds. The earliest effects we have observed are a decrease in the levels of NAD, ATP and other polyphosphorylated nucleotides, and an increase in pyrophosphate. Differences in nucleotide levels were detected as early as $30 \mathrm{~min}$ after phosphate addition. The common link between adenylate synthesis and NAD synthesis is 5'phospho- $\alpha$-D-ribose 1-pyrophosphate (PRPP). PRPP is synthesized from ribose $5^{\prime}$-phosphate and ATP. It is a key intermediate in the biosynthesis of purines and pyrimidines, as well as histidine and tryptophan (Stryer, 1981). Phosphonate may act directly on PRPP synthetase as a tight binding inhibitor. Alternatively, phosphonate may act on PRPP synthetase indirectly. For instance, a deficiency of pyruvate kinase in red blood cells results in lowered ATP and raised 2,3-phosphoglycerate levels (Tanaka \& Paglia, 1971). One would expect these cells to accumulate AMP and ADP as a result of their inability to regenerate ATP. Instead, the levels of all adenine nucleotides and of total NAD are decreased (Tanaka \& Paglia, 1971). The dissociation of PRPP synthetase is promoted by 2,3-phosphoglycerate, as well as by lowered ATP levels (Becker et al., 1977). Zerez et al. (1986) have suggested that it is the raised 2,3phosphoglycerate concentrations, rather than the lowered ATP levels, which are the major cause of the observed decrease in the adenine nucleotide pool in vivo. Regardless of the mechanism, inhibition at this site would reduce the pool sizes of adenylate nucleotides and NAD, and might be expected to have numerous effects on intermediary metabolism.

It is clear, however, that the effects of phosphonate on metabolism are relatively slow. Initially, the substitution of pyrophosphate or polyphosphate for ATP as a source of phosphoryl groups may minimize the effect of phosphonate on the ATP pool size (Harold, 1966; Kulaev \& Vagabov, 1983; Wood, 1985; Wood \& Clark, 1988). The observation that the levels of fructose 1,6bisphosphate did not alter significantly in the presence of phosphonate indicates that the early steps of glycolysis are not completely blocked. The raised pyrophosphate concentrations observed may result from either the inhibition of an as yet unidentified enzymic reaction, or the increased catabolism of tri- and higher polyphosphates. The latter explanation is compatible with the 
decrease in the average chain length of polyphosphate observed by Niere et al. (1990).

There was no increase in the pool sizes of ADP, AMP or adenosine as the pool size of ATP decreased. This indicates that the phosphorylation mechanism is intact in the presence of phosphonate. Further evidence for this interpretation is provided by the failure of phosphonate to alter phospholipid synthesis at this early stage. The pools of $\mathrm{C}_{5}$ and $\mathrm{C}_{6}$ sugars and sugar alcohols are also unchanged in the presence of phosphonate (R. H. Dunstan, personal communication).

We have found a number of compounds in the PCA extracts of $\mathrm{P}_{\mathrm{i}}$-starved mycelium which we have tentatively identified as polyphosphorylated nucleotides. These unusual nucleotides, colloquially known as 'alarmones', may act as signals for regulation (Rapaport \& Zamecnik, 1976; Zamecnik, 1983) and alert the cell to the onset of a particular stress (Bochner, 1987). Diadenosine $5^{\prime}, 5^{\prime \prime \prime} P^{1}, P^{4}$-tetraphosphate (AppppA), for instance, has been shown to activate DNA polymerase in $\mathrm{HeLa}$ cells (Rapaport et al., 1981). We are not aware of any reports of the effects of $P_{i}$-deprivation on the synthesis of alarmones in lower eukaryotes; however, $\mathrm{P}_{\mathrm{i}}$-deficiency did not produce increased levels of AppppA in the bacterium Salmonella typhimurium (Bochner et al., 1984). The dramatic reduction of the levels of the alarmones in the presence of phosphonate reported here may either be the result of a direct inhibition of the enzymes involved in their biosynthesis, or an indirect result of the reduction in adenylate pool size.

In conclusion, these results point to a specific site of action of phosphonate in $P$. palmivora - that of the synthesis of adenylate and a further possible site at the synthesis of the alarmones. The decreased level of ATP (but not energy charge) as a consequence of adenylate depletion may be minimized by the ability of the organism to use, in some reactions, polyphosphates rather than ATP as a source of high-energy phosphate bonds. However, as adenylate pool sizes are lowered, it could be anticipated that many synthetic reactions would be altered, accounting for the changes in the cell wall and cell surface polysaccharides already observed.

This work was supported by grants from the RCDF of the Reserve Bank, ASRRF and Albright \& Wilson (Aust.) Ltd. J. M. Griffith is a National Research Fellow. We wish to thank Dr B. Davidson for the [ ${ }^{32}$ P]ATP, and Dr R. H. Dunstan and Ms J. R. Iser for carrying out the GC-MS work. Mrs Siew Cleeland is thanked for skilful technical assistance.

\section{References}

ABU-JAWDAH, Y. (1983). Cell swelling of Colletotrichum lindemuthianum (Sacc. \& Magn.) Bri. \& Cav. induced by treatment of phosethyl-Al. Parasitica 39, 3-8.
Barchietto, T., Saindrenan, P. \& Bompeix, G. (1988). Uptake and utilisation of phosphonate ions by Phytophthora citrophthora and Nectria haemococca in relation to their selective toxicity. Pesticide Science 22, 159-167.

Barchietto, T., Saindrenan, P. \& Bompeix, G. (1989). Characterization of phosphonate uptake in two Phytophthora spp. and its inhibition by phosphate. Archives of Microbiology 151, 54-58.

Becker, M. A., Meyer, L. J., Huisman, W. H., Lazar, C. \& Adams, W. B. (1977). Human erythrocyte phosphoribosylpyrophosphate synthetase. Subunit analysis and states of subunit association. Journal of Biological Chemistry 252, 3911-3918.

BOCHNER, B. R. (1987). Global analysis of phosphorylated metabolites to search for alarmones. In Phosphate Metabolism and Cellular Regulation in Microorganisms, pp. 289-294. Edited by A. TorrianiGorini, F. G. Rothman, S. Silver, A. Wright \& E. Yagil. Washington, DC: American Society for Microbiology.

BOCHNER, B. R., MARON, D. M. \& AMES, B. N. (1981). Detection of phosphate esters on chromatograms: an improved reagent. Analytical Biochemistry 117, 81-83.

Bochner, B. R., LeE, P. C., Wilson, S. W., Cutler, C. W. \& Ames, B. N. (1984). AppppA and related adenylated nucleotides are synthesized as a consequence of oxidation stress. Cell 37, 225232.

Cashel, M. \& Gallant, J. (1969). Two compounds implicated in the function of the RC gene of Escherichia coli. Nature, London 221, 838-841.

CofFEY, M. D. \& JosePH, M. C. (1985). Effects of phosphorous acid and Fosetyl-Al on the life cycle of Phytophthora cinnamomi and $P$. citricola. Phytopathology 75, 1042-1046.

CoHEN, Y. \& COFFEY, M. D. (1986). Systemic fungicides and the control of Oomycetes. Annual Review of Phytopathology 24, 311-338.

Creamer, J. R. \& Bostock, R. M. (1986). Characterization and biological activity of Phytophthora infestans phospholipids in the hypersensitive response of potato tuber. Physiological and Molecular Plant Pathology 28, 215-225.

Dercks, W. \& Buchenauer, H. (1987). Comparative studies on the mode of action of aluminium ethyl phosphite in four Phytophthora species. Crop Protection 6, 82-89.

DeRCKS, W. \& CREASER, L. L. (1989). Influence of fosetyl-Al on phytoalexin accumulation in the Plasmopara viticola-grape vine interaction. Physiological and Molecular Plant Pathology 34, 203213.

Grant, B. R., Griffith, J. M., IRving, H. R. \& RadDA, M. (1984). An improved method for the synchronous production of zoospores from Phytophthora palmivora. Experimental Mycology 10, 382-385.

GRANT, B. R., IRVING, H. R. \& RADDA, M. (1985). The effect of pectin and related compounds on encystment of Phytophthora palmivora. Journal of General Microbiology 131, 669-676.

Griffith, J. M., Smillie, R. H., Niere, J. O. \& Grant, B. R. (1989a). Effect of phosphate on the toxicity of phosphite in Phytophthora palmivora. Archives of Microbiology 152, 425-429.

Griffith, J. M., AkINs, L. A. \& Grant, B. R. (1989 $b$ ). Properties of the phosphate and phosphite transport systems of Phytophthora palmivora. Archives of Microbiology 152, 430-436.

HAROLD, F. M. (1966). Inorganic polyphosphates in biology: structure, metabolism, and function. Bacteriological Reviews 30, 772-794.

HENDRIX, J. W. \& Rouser, G. (1976). Polar lipids of Phytophthora parasitica var. nicotianae, in comparison with those of selected other fungi. Mycologia 68, 354-361.

KATES, M. (1982). Techniques of lipidology. Isolation, analysis and identification of lipids. In Laboratory Techniques in Biochemistry and Molecular Biology, vol. 3, part II, pp. 502-579. Edited by T. S. Work \& E. Work. Amsterdam: North-Holland Publishing Co.

Kulaev, I. G. \& VaGabov, V. M. (1983). Polyphosphate metabolism in micro-organisms. Advances in Microbial Physiology 24, 83-171.

LeE, P. C., Bochner, B. R. \& AMEs, B. N. (1983). Diadenosine $5^{\prime}, 5^{\prime \prime \prime}-P^{1}, P^{4}$-tetraphosphate and related adenylated nucleotides in Salmonella typhimurium. Journal of Biological Chemistry 258, $6827-6834$.

LusBy, E. W. \& MCLAUGhLIN, C. S. (1980). The metabolic properties of acid soluble polyphosphates in Saccharomyces cerevisiae. Molecular and General Genetics 178, 69-76. 
Nelson, D. L. \& Kornberg, A. (1970). Biochemical studies of bacterial sporulation and germination. XIX. Phosphate metabolism during sporulation. Journal of Biological Chemistry 245, 11371145.

Niere, J. O., GrifFith, J. M. \& GRANT, B. R. (1990). ${ }^{31}$ P NMR studies on the effect of phosphite on Phytophthora palmivora. Journal of General Microbiology 136, 147-156.

Ouimette, D. G. \& Coffey, M. D. (1989). Phosphonate levels in avocado (Persea americana) seedlings and soil following treatment with Fosetyl-Al or potassium phosphonate. Plant Disease 73, 212-215.

PAYNe, S. M. \& AMES, B. N. (1982). A procedure for rapid extraction and high-pressure liquid chromatographic separation of the nucleotides and other small molecules from bacterial cells. Analytical Biochemistry 123, 151-161

PegG, K. G., Whiley, A. W., Saranah, J. B. \& Glass, R. J. (1985). Control of Phytophthora root rot of avocado with phosphorous acid. Australasian Plant Pathology 14, 25-29.

Randerath, E. \& Randerath, K. (1964). Resolution of complex nucleotide mixtures by two-dimensional anion-exchange thin-layer chromatography. Journal of Chromatography 16, 126-129.

RAPAPORT, E. \& ZAMECNIK, P. C. (1976). Presence of diadenosine $5^{\prime}, 5^{\prime \prime \prime}-P^{1}, P^{4}$-tetraphosphate $\left(\mathrm{Ap}_{4}\right)$ in mammalian cells in levels varying widely with proliferative activity of the tissue: a possible positive 'pleiotypic activator'. Proceedings of the National Academy of Sciences of the United States of America 73, 3984-3988.

RAPAPORT, E., ZAMECNIK, P. C. \& BARIL, E. F. (1981). Association of diadenosine $5^{\prime}, 5^{\prime \prime \prime}-P^{1}, P^{4}$-tetraphosphate binding protein with HeLa cell DNA polymerase a. Journal of Biological Chemistry 256, 12148-12151.

RENKONEN, O. \& LUUKKONEN, A. (1976). Thin-layer chromatography of phospholipids and glycolipids. In Lipid Chromatographic Analysis, 2nd edn, vol. 1, pp. 1-58. Edited by G. V. Marinetti. New York: Dekker.

RoHRBACH, K. G. \& SCHENCK, S. (1985). Control of pineapple heart rot, caused by Phytophthora parisitica and $P$. cinnamomi, with metalaxyl, fosetyl-Al, and phosphorous acid. Plant Diseases 69, 320-323.

ROSENBERG, H. (1959). The detection of phosphate on chromatograms. Journal of Chromatography 2, 487-489.

Saindrenan, P., Barchietto, T., Avelino, J. \& Bompeix, G. (1988). Effects of phosphite on phytoalexin accumulation in leaves of cowpea infected with Phytophthora cryptogea. Physiological and Molecular Plant Pathology 32, 425-435.

Schwinn, F. \& Staub, T. (1987). Phenylamides and other fungicides against oomycetes. In Modern Selective Fungicides - Properties, Applications, Mechanisms of Action, pp. 259-274. Edited by H. Lyr. Harlow: Longman Scientific \& Technical.

SchwinN, F. J. \& UReCh, P. A. (1986). Progress in the chemical control of diseases caused by Oomycetes. In Fungicide Chemistry: Advances and Practical Applications (ACS Symposium no. 304), pp. 89-106. Edited by M. B. Green \& D. A. Spilker. Washington DC: American Chemical Society.

Smillie, R., Grant, B. R. \& Guest, D. (1989a). The mode of action of phosphite: evidence for both direct and indirect modes of action on three Phytophthora spp. in plants. Phytopathology 79, 921-926.

Smillie, R. H., Dunstan, R. H., Grant, B. R., Griffith, J. M., Iser, J. \& NIERE, J. O. (1989b). The mode of action of the antifungal agent phosphite. Abstracts, Mediterranean Phytopathological Union Conference on Phytophthora diseases of citrus and other crops in the Mediterranean area. Palermo, Sicily, 18-22 April, 1989, p. 69.

STRYER, L. (1981). Biochemistry. 2nd edn. San Francisco: W. H. Freeman.

Tanaka, K. R. \& Paglia D. E. (1981). Pyruvate kinase deficiency. Seminars in Hematology 8, 367-396.

WALKER, G. E. (1988). Control of carrot cavity spot with metalaxyl and phosphorous acid. Australasian Plant Pathology 17, 41-43.

WASSEF, M. K. \& HENDRIX, J. W. (1977). Ceramide aminoethylphosphonate in the fungus Pythium prolatum. Biochimica et Biophysica Acta 486, 172-178.

Williams, D. J., Beach, B. G. W., Horriere, D. \& Marechal, G. (1977). LS74-783, a new systemic fungicide with activity against Phycomycete diseases. Proceedings of the British Crop Protection Conferences 2, 565-573.

WoOD, H. G. (1985). Inorganic pyrophosphate and polyphosphates as sources of energy. Current Topics in Cellular Regulation 26, 355-369.

WOOD, H. G. \& CLARK, J. E. (1988). Biological aspects of inorganic polyphosphates. Annual Review of Biochemistry 57, 235-260.

ZAMECNIK, P. (1983). Diadenosine $5^{\prime}, 5^{\prime \prime \prime}-P^{1}, P^{4}$-tetraphosphate $\left(\mathrm{Ap}_{4}\right)$ : its role in cellular metabolism. Analytical Biochemistry 134, 1-10.

Zerez, C. R., Lachant, N. A. \& TanaKa, R. (1986). Decrease in subunit aggregation of phosphoribosylpyrophosphate synthetase: a mechanism for decreased nucleotide concentrations in pyruvate kinase deficient human erythrocytes. Blood 68, 1024-1029. 